\title{
EVALUATING THE LEAN-ENABLING COMPETENCIES OF CLIENTS
}

\author{
Yara Daoud ${ }^{1}$, Carla Ghannoum ${ }^{2}$, Soheila Antar ${ }^{3}$ and Farook Hamzeh ${ }^{4}$
}

\begin{abstract}
The principles of lean thinking are rapidly gaining the attention of construction companies while client-side organizations are not catching up at the same pace. However, the client plays a crucial role in driving and setting the framework of the process throughout all phases of the project and thus has a critical influence on the successful implementation of lean. This issue has not been given enough attention in literature, especially in the Middle East. Hence, this study aims at identifying the current status of Middle Eastern clients' characteristics, behaviors and practices throughout the different phases of a construction project. The paper investigates the lean-enabling competencies of clients from the perspective of designers and contractors through online data collection surveys. The results revealed that clients were regarded by AECs as being knowledgeable and involved. However, it appears they persist in taking unilateral decisions, especially regarding deadlines, and focusing on short-term financial goals while neglecting the importance of enforcing collaboration measures.
\end{abstract}

\section{KEYWORDS}

Clients, Lean construction, Middle East, Collaboration, Value

\section{INTRODUCTION}

For years, lean thinking has been successfully applied in the construction industry bringing improvements to both the planning and execution of projects. Womack and Jones (1996) emphasized value as the primary principle of lean thinking and defined it as the first of the five steps of lean implementation. Value is directly correlated with client requirements making the client's role central to the success or failure of any project, particularly a construction project. Clients are responsible for driving and setting the framework of the process throughout all phases of the project, and their needs must be set and accurately understood to maximize value and minimize waste. However, the current literature does not widely discuss the issue of clients and emphasizes instead on implementing lean principles and tools within design companies or contracting firms. Therefore, while Lean Construction is becoming more and more popular with construction companies, client-side organizations are not catching up at the same pace (Dlouhy et al. 2017). Additionally, the client is often mistaken to be a

1 Graduate Student, Dept. of Civil and Environmental Engineering, American University of Beirut, Beirut, Lebanon, +961 70 063008, ynd02@ mail.aub.edu

2 PhD Student, Dept. of Civil and Environmental Engineering, American University of Beirut, Beirut, Lebanon,+9613350362, cma25@mail.aub.edu

3 Graduate Student, Dept. of Civil and Environmental Engineering, American University of Beirut, Beirut, Lebanon,+961 3540882 , sza16@mail.aub.edu

4 Associate Professor, Civil and Environmental Engineering Dept., University of Alberta, Canada, hamzeh@ualberta.ca 
single-entity, while in fact this client is usually a representative of different values, interests and time perspectives (Bertelsen and Emmitt 2005). This can be particularly problematic for Architectural and Engineering (AE) firms and General Contractors (GC) since the nature, behaviour, and the level of knowledge of the client can highly impact the flow and success of the project.

\section{Client Role, Competencies and Impact on the Project}

Tzortzopoulos et al. (2006) summarized the activities that clients should perform to lead a successful project. These activities include: choosing the suitable participants for each project, comprehensive understanding of the construction process in order to set reasonable timescales and milestones, well coordination and cooperation with different stakeholders throughout the project while clearly defining roles and responsibilities, adopting a sound decision-making process, being aware of project constraints, and commitment to the project.

An example of a knowledgeable client who has succeeded in managing and producing successful projects in terms of quality, cost, time, and safety is Sutter Health, a health care provider in California. Their approach to lean implementation is based on "The Five Big ideas" which aim at generating the highest value for all stakeholders. The organization selects the project team based on quality evaluation, promotes a collaborative design environment, makes sure that all key stakeholders are involved early on and during all the phases of the project, and encourages innovation and employee empowerment. This is achieved using lean-enabling tools such as Integrated Project Delivery (IPD), The Last Planner System, Building Information Modeling (BIM), and Target Value Design. Moreover, their contracts distribute both risks and rewards between stakeholders to align interests and unify goals (Lichtig 2005; Sinclair 2012).

Other client organizations are attempting to follow the lean path but still have a long way to go. For example, the status of 8 client organizations implementing lean in Germany was analysed in order to specify their lean maturity. The results show that only one of the 8 companies reaches a maturity level of "Lean Organized" (i.e. accepting lean principles and implementing them regularly) while the others are still at more primitive levels (Dlouhy et al. 2017). Bolpagni et al. (2017) also studied the level of maturity of the integration of lean construction and BIM in a client organization in Massachusetts. The authors concluded that an internal change in client organizations is empirical, where traditional procurement practices as well as traditional contracts should be modified in order to support BIM and lean.

Moreover, reasons for delays and cost overruns in construction projects have been divided in literature to those that are directly related to client actions and characteristics, and those that are related to the actions of other stakeholders. Samarghandi et al. (2016) found that the probability of occurrence of delays due to owner defects ranked before those related to the contractor and the consultant. Similarly, in a study about delay causes in Egyptian construction projects, owner related causes were ranked "Very High" relative to their frequency of occurrence, while those of the contractor ranked "High" and of the consultant ranked "Low" (Marzouk and El-Rasas 2014). However, Sutter Health have proved that wise and knowledgeable owners can mitigate the factors that hinder the project success. Owners can even control factors that are not directly related to them through effective management of the relationship between stakeholders. 


\section{Middle East Status Quo}

The Middle East (ME) region, consisting of the Gulf Cooperation Council (GCC), North Africa and a few countries in Asia, is presently witnessing an upsurge in the construction industry (Fahy 2017). According to a report by Harris (2013), 117 major construction projects with a total cost of 1 trillion US dollars are currently ongoing in the region and planned for completion by 2030 . However, this growth is accompanied with various cultural and technical barriers that can hinder successful project completion and ultimately lean implementation in the region. These barriers are observed at both AEC and client organizations and they include: cultural aspects, governing project delivery methods as well as knowledge and implementation of latest industry technologies.

To begin with, the ME region exhibits several cultural traits that can largely impact any construction project. In a study on global leadership, the ME cluster was one of the cultural clusters that scored low in terms of pertinent attributes such as team orientation, uncertainty avoidance and future orientation (Javidan et al. 2006). Another relevant cultural aspect is that of inertia where the Middle Eastern society, similar to other comparable societies, is found to be hesitant of change (Littrell and Bertsch 2013). Moreover, corruption was observed in the Lebanese construction industry, a representative part of the ME industry (Rizk et al. 2018).

As for governing delivery methods, the majority of projects in the region still adopt the traditional project delivery method instead of IPD (Rached et al. 2014). The latter encourages driving value and eliminating waste through collaboration and mutual trust of the different stakeholders (AIA 2007). Thus, opting for a traditional delivery method can highly impact time, cost and efficiency of the project.

In terms of latest industry knowhow, an investigation conducted on the implementation of BIM in the ME showed that only $20 \%$ of the AEC firms in the region are currently using or in the process of adopting BIM technology (Gerges et al. 2017). Moreover, people only perceive it as an "advanced AutoCAD tool" and are thus not fully utilizing the capabilities of this tool in increasing efficiency and promoting collaboration in early project phases.

\section{ObJectives ANd Paper Organization}

Since the key to the success on any project lies in the hands of clients, their role remains crucial in both initiating and promoting lean construction throughout the life cycle of the project. The literature, however, lacks studies related to client organizations in the construction industry especially in the context of the ME. This study therefore sets out to evaluate the current status of Middle Eastern clients' characteristics, practices, and activities throughout the phases of a construction project. The aim is to assess how close the client competencies are to facilitating the implementation of lean construction in the ME with respect to different project participants, namely designers and contactors. This paper begins with the research methodology adopted in this study followed by the key findings and the corresponding analysis. Finally, study limitations, conclusions and future work recommendations are presented.

\section{METHODOLOGY}

In order to gain further insight into the issue of lean-enabling client competencies, an online survey was conducted among $\mathrm{AE}$ consulting firms as well as contracting 
companies operating in the ME region. The aim was to assess how clients performed on specific projects and how their behavior affected the overall project performance in light of lean values. Since questioning clients about their own conduct would lead to a natural positive bias, it was decided to carry out this assessment from the more objective perspective of the expert engineers (over 10 years of experience) who worked at length with them on behalf of their respective AE or contracting firms. Furthermore, as the role of the client is most critical in large, complex and multidisciplinary projects, the firms selected were chosen with a relatively large volume of work to ensure their projects are medium to large-scale.

To achieve the objectives of this study, a thorough literature review was first conducted in order to identify the possible lean competencies of clients. Based on the findings and the authors' own experience in the field, the most relevant factors related to client role and impact were divided into 2 separate groups. The first group contains 4 categories of aspects that are directly related to clients (their own characteristics and traits). These categories are: Knowledge \& Involvement, Requirements \& Transparency, Decision Making, and Value. The second group is related to the actions and characteristics of other stakeholders but that the client can impact and successfully manage: Collaboration \& Relationships. Table 1 shows a detailed description of the categorisation.

Next, specific questions related to each aspect in the table were prepared followed by the formulation of the survey which consists of two main sections. The first part of the questionnaire includes demographic as well as general questions to gain more background information about the projects, the Architecture Engineering Construction (AEC) firms and the client organizations. General questions are related to the organizational structure of the AEC firms, the client type, the project size as well as project award and delivery method and the like. As for the second part of the questionnaire, it includes the prepared questions related to the expert engineers' perceptions of the client competencies and their impact on the project performance. The respondents were asked to select a specific recent project (less than five years) they worked on and to answer a number of questions related to the way the client approached and dealt with various aspects of the project. Based on their replies, it was ascertained how closely the client practices were aligned with lean principles. In total, the survey was comprised of 28 questions of which 26 were closed and 2 were open-ended. The closed questions included 6 matrix questions and were all recorded in the five-point Likert scale to ensure accurate mapping.

An online structured cross-sectional survey was adopted to enable easy access to respondents. To select the respondents, purposive non-probability critical sampling was adopted based on the researchers' "knowledge of the population and the objectives of the research" (Wilson 2014). Moreover, to facilitate the search for qualified participants, snowball sampling was used whereby the survey was initiated with a few people who were then asked to recommend others with similar profiles (Wilson 2014). The final sample size of this study was 47 respondents. It is also noteworthy that the questionnaire was developed to suit the Middle Eastern construction industry. For instance, general terminology was used to prevent possible confusion among respondents unfamiliar with lean related jargon. In a final note, the protection and confidentiality of respondents was ensured through an informed consent form and by keeping their identities anonymous. 


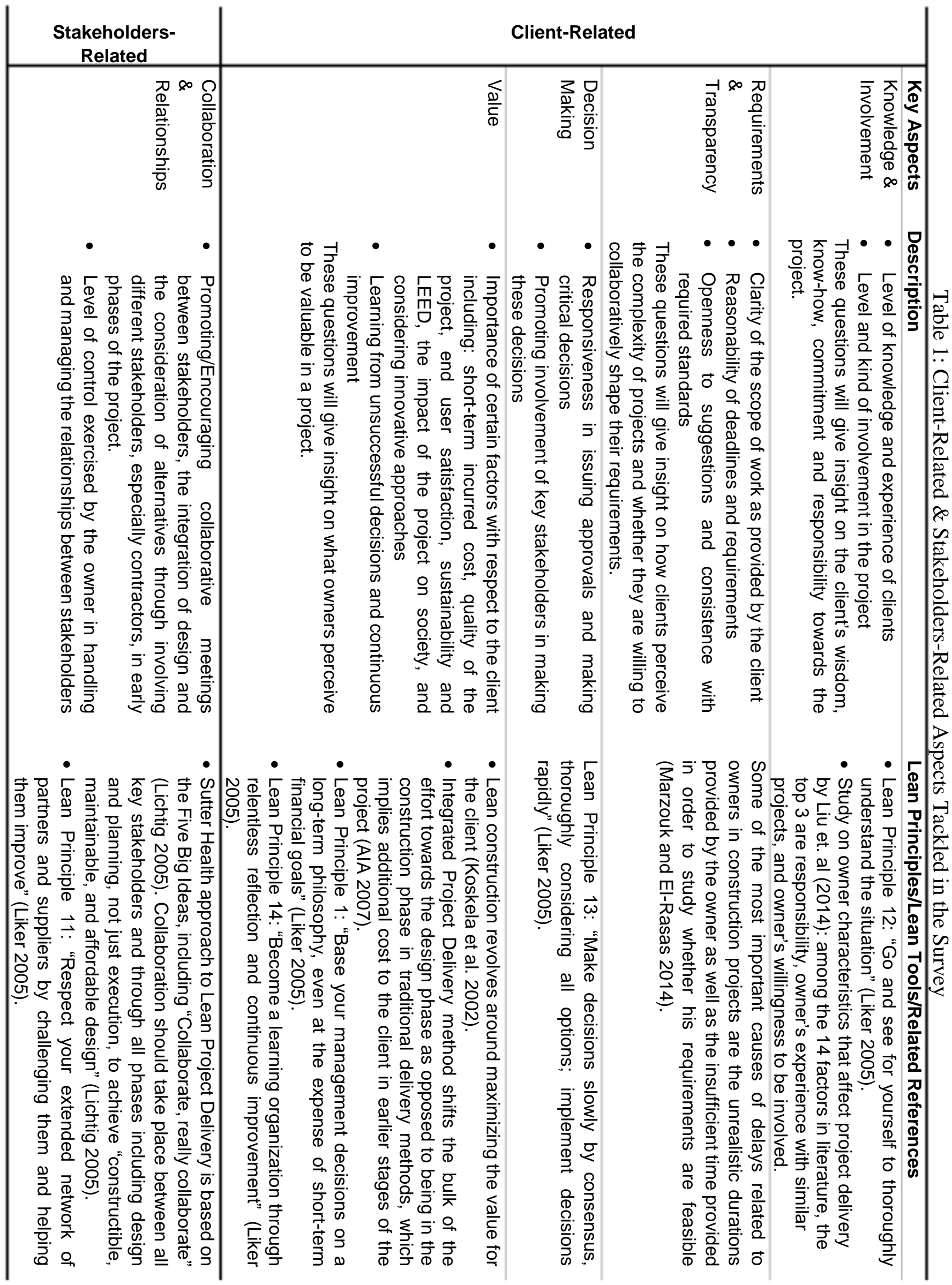




\section{RESULTS AND DISCUSSIONS}

\section{RESPONDENTS, THEIR FIRMS AND SELECTED PROJECTS}

In total, approximately 250 surveys were sent out and 47 valid replies were received which corresponds to an approximate return rate of $19 \%$ where $68 \%$ of the respondents belong to AE design firms while the rest worked for GC firms. The expert engineers and architects surveyed were all active in the field for more than 10 years with $41 \%$ having 15 to 20 years of experience and $28 \%$ having more than 20 years.

As for the organizational structure of the AEC firms, $72 \%$ were department-based while only $19 \%$ had a project-based structure and the rest were hybrids. It is noted that the most common structure observed, the department-based, is the type that least promotes an effective implementation of lean since the foremost loyalty of the teams remains to their departments rather than to the project as a whole.

The projects chosen by the respondents were all located in the ME and belonged to various construction sectors including commercial, institutional, residential, heavy civil, infrastructure and industrial. They were medium to large-scale jobs with total costs exceeding 4 million USD, of which 55\% had a budget 50 to 500 million USD while $13 \%$ had a cost exceeding 500 million USD.

Figure 1 shows the delivery method of the chosen projects chosen while Figure 2 assesses knowledge and experience in lean and IPD.
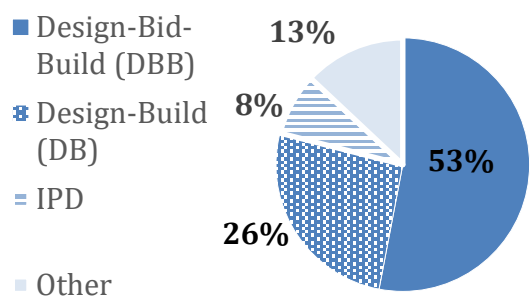

Figure 1: Project Delivery Method of Selected Project

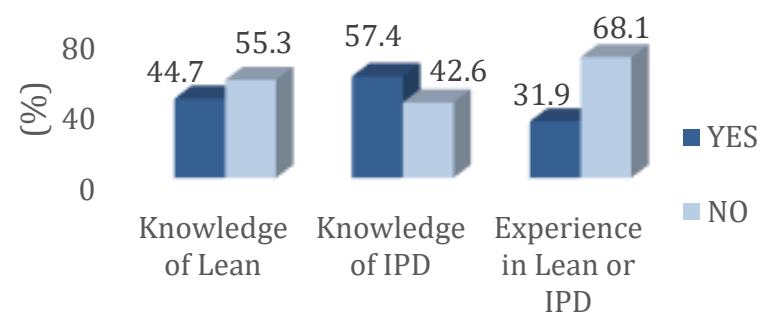

Figure 2: Respondents Knowledge \& Experience in Lean and IPD in ME

The illustrated results show that the traditional delivery methods such as the DesignBid-Build (DBB) and the Design-Build (DB) remain the most widely adopted. This validates previous studies conducted on the governing project delivery methods in the ME, which are mentioned in the Middle East Status Quo section of this paper. Moreover, more people declared having knowledge of IPD than knowledge of lean. This indicates that some of the respondents are not aware that IPD is based on lean principles or have confused IPD with Integrated Design Projects (IDP).

\section{OWNERS AND THEIR REPRESENTATIVES}

The clients selected by the participants were either from the private sector as developers $(68 \%)$ or contractors $(17 \%)$, or from the public sector $(15 \%)$. The client representatives were mostly from the client organization (55\%), e.g. an engineer or the owner himself, or from a PM firm appointed by the client (45\%). 


\section{OWNER Related FACTORS}

\section{Knowledge and Involvement}

The respondents were asked to rank the various factors related to the knowledge and involvement of the client in the project on a five-point Likert scale, ranging from Strongly Agree (S.A.) to Strongly Disagree (S.D.).

Results in Figure 3 show that the respondents mostly agreed that the client was informed and knowledgeable. A natural outcome is the ability of the client/client representative to provide a clear scope of work to stakeholders and be actively involved in his project which is confirmed in the same figure where the three metrics followed a similar trend. When the results are divided between those of AEs and GCs, it can be observed from figures 4, 5 and 6 that the client was generally viewed as more informed and involved by the GCs than by the AEs especially for the case of the scope of work where $94 \%$ of GCs agreed it was clear as compared to a $75 \%$ agreement by AEs.

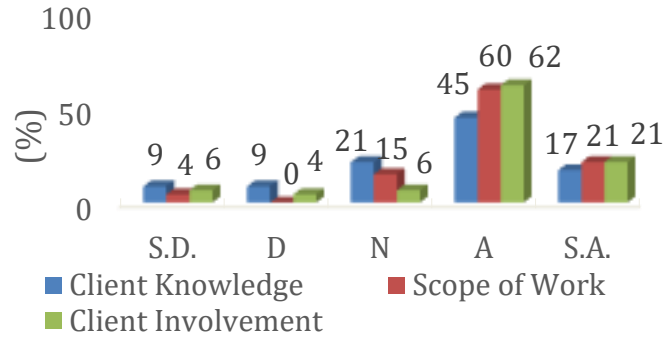

Figure 3: Summary of the Three Client Metrics Shown in Figures 4, 5 \& 6

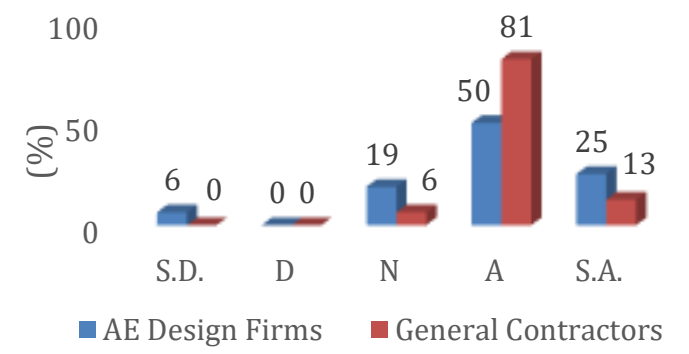

Figure 5: Scope of Work Required from AEC as Specified by Client was Clear

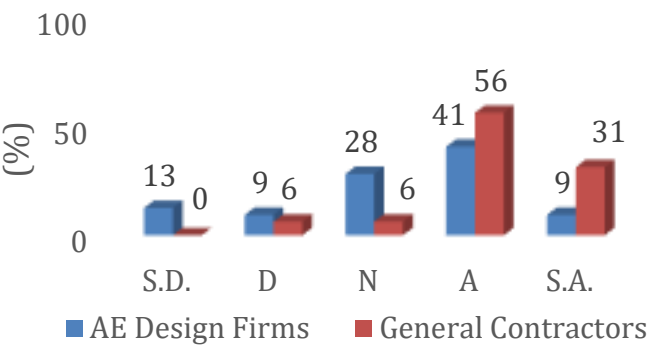

Figure 4: Client was Informed \& Knowledgeable about Similar Projects

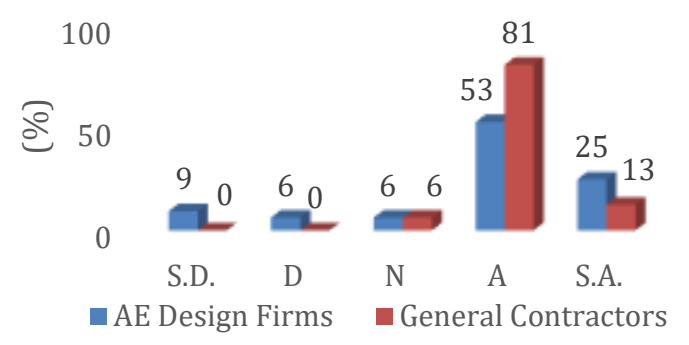

Figure 6: The Client/Client Rep. was Actively Involved in All Project Phases

One of the most crucial roles required from $\mathrm{AE}$ firms is assisting the client to learn and develop his requirements and to translate his purposes into values and then into clearly defined specifications. This process is necessary to ensure that the client gets what he wants but it is highly iterative. This would explain why more GCs than AEs saw that the scope of work provided by the client was clear since by the time a project reaches the construction phase it would have relatively matured.

\section{Requirements and Transparency}

As a natural result of being knowledgeable and involved, clients are found to be consistent with their standards and open to suggestions, as shown in Figure 7. However, only $47 \%$ of the respondents viewed client requirements, although clear, as being reasonable and a lower 35\% saw the deadlines set by the clients as achievable. This is in line with previous findings that important causes of owner delays are the unrealistic 
durations they set for their projects as well as the insufficient time provided for AECs to study the feasibility of owner requirements (Marzouk and El-Rasas 2014). It is rather contradicting, nevertheless, that the client is knowledgeable and open to suggestions but still imposes unrealistic requirements and timelines on the project team. A client who understands the design and construction process and is willing to accept the opinions of the professionals working on the project should be able to set realistic requirements collaboratively with the remaining stakeholders.

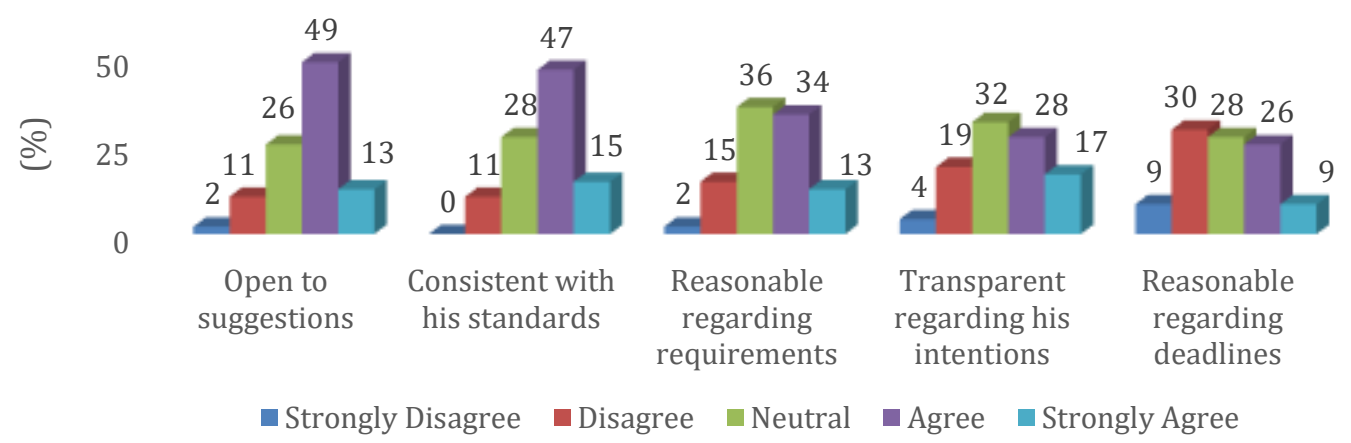

Figure 7: The Clients Attitude and Behavior as Seen by AEC Firms

Furthermore, only few respondents viewed clients as being transparent regarding their intentions, a cornerstone in building long term relationships based on mutual trust and respect.

\section{Decision making}

In total, $51 \%$ of respondents viewed the client as being responsive while $34 \%$ believed he was prone to issue frequent and unreasonable variation orders. Whether the client issues approvals and takes critical decisions in a timely manner bares a direct impact on the project schedule. Given that the client is the party most affected by unwarranted delays, it is surprising to see such numbers. However, a closer look at the results reveals that among the 29 respondents who said the client was well informed, $62 \%$ indicated the latter was responsive in taking decisions. Thus, informed clients are more comfortable and better equipped to take timely decisions probably since they understand well the implications on the progress of the project.

Moreover, even though involving stakeholders in major decisions related to them would benefit the project as a whole, only $46 \%$ of participants agreed that the client actually does that.

\section{Value}

Results listed in Table 2 show that clients consider the project quality and end user satisfaction to be important which is in line with lean principles. However, the remaining factors reveal that some values of ME clients are not aligned with those of lean. Giving high importance to short term costs does not comply with lean principles. Similarly, neglecting the importance of innovative approaches and actively learning from errors are contrary to lean principle 14 relating to relentless reflection and continuous improvement (Liker 2005). 
Table 2: Value as seen by AEC firms

\begin{tabular}{ll}
\hline Factors ranked according to their importance to the Client & Mean rate (/5) \\
\hline Quality of the project & 4.26 \\
End user satisfaction & 4.09 \\
Short-term incurred costs & 4.02 \\
Building long-term relationships with stakeholders based on trust & 3.36 \\
Considering innovative approaches & 3.30 \\
Learning from design/construction errors and unsuccessful decisions & 3.28 \\
for continuous improvement & \\
Impact of the project on society & 3.15 \\
Sustainability and LEED design & 3.02 \\
\hline
\end{tabular}

\section{STAKEHOLDERS RELATED FACTORS MANAGED BY THE ClIENT}

\section{Collaboration \& Relationships}

Few respondents agreed that clients were clear advocates of collaboration measures, as shown in Figure 8.

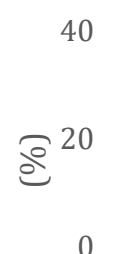
0

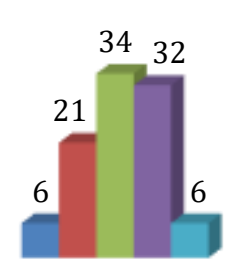

$$
\begin{aligned}
& \text { Early } \\
& \text { volvement of }
\end{aligned}
$$$$
\text { stakeholders }
$$

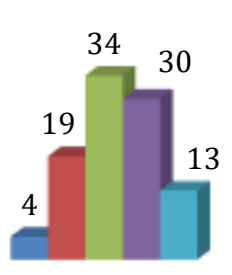

Exploration of alternatives in early phases

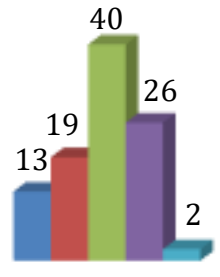

Involvement of stakeholders in alternatives

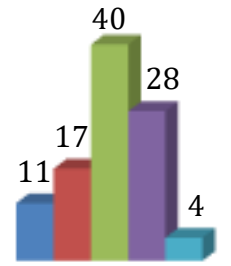

An integrated design approach

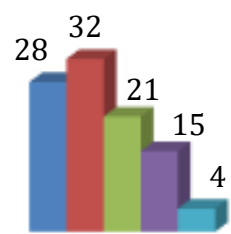

Use of BIM Technologies
- Strongly Disagree $\quad$ Disagree $\quad$ Neutral

Figure 8: The Clients Promotion of Collaboration

Moreover, when asked if and when collaboration meetings were called for by the client, $66 \%$ of respondents acknowledged having participated in some kind of collaborative meetings during construction. While $42 \%$ were involved in such meetings in the Design Development and Final Design phases, only $28 \%$ were implicated in the Project Definition stage and $13 \%$ said no collaborative meetings were held. This confirms that collaboration meetings, if held, were usually at later stages of the project, which is common in traditional delivery methods. This is in line with (Dettman and Bayer 2012), who state that "Traditional contractual and project management systems establish vertical silos of parties and management structures... Their [the people] communication and decision making tend to be vertical — up and down each silo's chain of command, and then over and up/down to another organizational silo". Therefore, although collaboration attempts were made, they cannot reach their full potential since the loyalty of parties remains to their own firms rather than to the project as a whole.

It is encouraging to see though that some of the ME clients, as shown in Figure 9, seem to endorse, at least to some extent lean principle 11 of respecting and challenging your partners. Still, clients need to take a step further to achieve the desired results of long-term relationships away from the adversarial and claim/dispute-oriented relations that now govern traditional project delivery approaches widely adopted in the ME. 


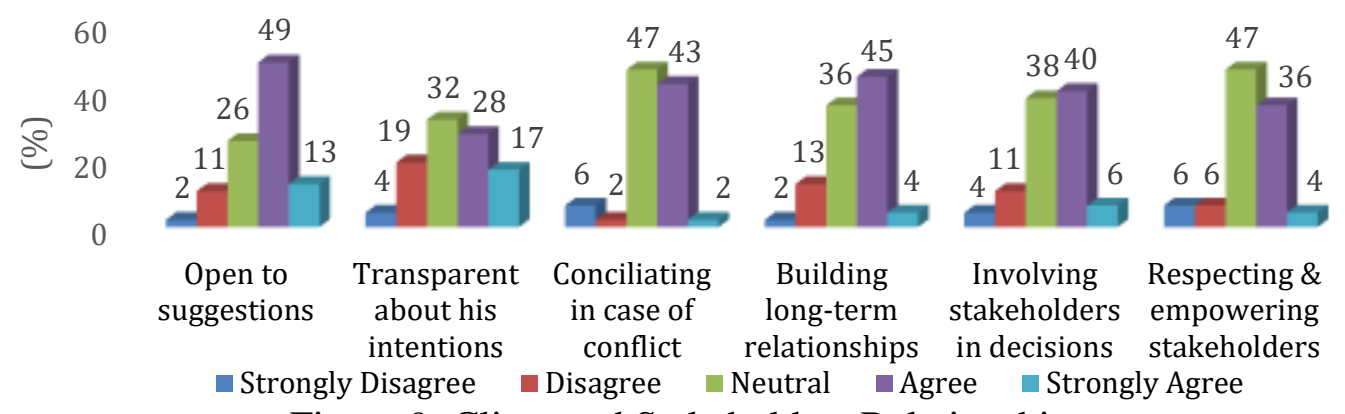

Figure 9: Client and Stakeholders Relationships

\section{LIMITATIONS}

The bidding practices and appointment criteria commonly used by the client are key factors that provide insight on client ethics and perception of value. However, since AEs and contractors theoretically cannot know these issues about the client organizations, these questions were not addressed. Moreover, like any study involving assessment of human behavior, there is always bias in the results obtained.

\section{CONCLUSIONS AND RECOMMENDATIONS}

Overall, the results revealed that clients in the ME were regarded positively by AECs as being knowledgeable, well informed and actively involved in their projects. However, it appears most owners persist on taking unilateral decisions instead of involving stakeholders and enforcing a team decision making process. Moreover, a number of current client practices were not in line with lean principles such as focusing on shortterm financial goals instead of a long-term philosophy. Innovation, set-based design and continuous learning did not score high on their value scale. Also, clients were often not seen as actively enforcing collaboration measures such as early involvement of stakeholders, adoption of an integrated design and use of BIM.

From the findings of this study, it may be concluded that, in general, clients are either unaware of lean construction or do not have a deep understanding of its underlying principles. Some of the undeniable benefits of adopting lean in the ME construction industry include gaining better control over projects, maximizing value, reducing waste and successfully completing the project both on time and below target cost. Claims, disputes and adversarial relationships can be replaced by long-term relationships with stakeholders based on mutual respect and trust. However, clients and AECs must undertake radical changes to their way of thinking, traditional methods and organizational structures to achieve that. Before embarking on this journey, both the owners and AECs should be educated about lean concepts, tools and language. This training should further help parties to overcome cultural barriers such as resistance to change, in-group collectivism and a focus on short-term goals.

The authors hope that this assessment of the client lean-enabling competencies provides a basis for future research into this critical area which has not been documented to the extent it merits. An interesting point to consider is the standards to which the AECs evaluated their clients. It would be only natural for them to rank the selected client with respect to others they previously worked with. So, had the AECs been familiar with clients who fully embrace and practice lean principles, such as Sutter Health, would they have rated their clients differently? 


\section{REFERENCES}

American Institute of Architects (2007). "Integrated project delivery: A guide.", 1-61.

Bertelsen, S., and Emmitt, S. (2005) "The client as a complex system." Proc., 13th International Group for Lean Construction Conference, International Group on Lean Construction, Sydney, Australia, 73-79.

Bolpagni, M., Burdi, L., and Ciribini, A. L. C. (2017). "Integration of Lean Construction and Building Information Modeling in a Large Client Organization in Massachusetts." Proc., 25th Annual Conference of the International Group for Lean Construction, International Group on Lean Construction, Heraklion, Greece, 79-86.

Dettman, K., and Bayer, D. (2012). "Alignment partnering: A bridge to ADR processes?" Journal of Legal Affairs and Dispute Resolution in Engineering and Construction, 5(2), 60-66.

Dlouhy, J., Binninger, M., Weichner, L., and Haghsheno, S. (2017). "Implementation of Lean Construction in Client Organizations - an Analysis of the Status Quo in Germany." Proc., 25th Annual Conference of the International Group for Lean Construction, International Group on Lean Construction, Heraklion, Greece, 275-282.

Fahy, M. (2017). "Analysis: Middle East construction industry expects good growth in 2014." Arabian Industry, $<$ https://www.arabianindustry.com/construction/features/2014/jan/12/analysismiddle-east-construction-industry-expects-good-growth-in-2014-4561960/> (Nov. 17, 2018).

Gerges, M., Austin, S., Mayouf, M., Ahiakwo, O., Jaeger, M., Saad, A., and Gohary, T.-E. (2017). "An investigation into the implementation of Building Information Modeling in the Middle East." Journal of Information Technology in Construction (ITcon), 22(1), 1-15.

Harris, E. (2013). "Middle East Major Construction Programmes Mitigating the Delivery Risk." Middle East Business, <http://middleeastbusiness.com/middle-east-major-construction-programmes/> (Nov. 30, 2018).

Javidan, M., Dorfman, P. W., De Luque, M. S., and House, R. J. (2006). "In the eye of the beholder: Cross cultural lessons in leadership from project GLOBE." Academy of management perspectives, 20(1), 67-90.

Koskela, L., Howell, G., Ballard, G., and Tommelein, I. (2002). "The foundations of lean construction." Design and construction: Building in value, 211-226.

Lichtig, W. A. (2005). "Sutter health: Developing a contracting model to support lean project delivery." Lean Construction Journal, 2(1), 105-112.

Liker, J. K. (2005). The toyota way, 1st Ed., Esensi, 1-389.

Littrell, R. F., and Bertsch, A. (2013). "UN Millennium Development Goals and gender equality in employment in the Middle East." Foresight, 15(4), 249-263.

Liu, B., Huo, T., Shen, Q., Yang, Z., Meng, J., and Xue, B. (2014). "Which owner characteristics are key factors affecting project delivery system decision making? Empirical analysis based on the rough set theory." Journal of management in engineering, 31(4), 05014018.

Marzouk, M. M., and El-Rasas, T. I. (2014). "Analyzing delay causes in Egyptian construction projects." Journal of advanced research, 5(1), 49-55. 
Rached, F., Hraoui, Y., Karam, A., and Hamzeh, F. (2014). "Implementation of IPD in the Middle East and its challenges." Proc., 22nd annual conference of the international group for Lean construction, International Group on Lean Construction, Oslo, Norway, 293-304.

Rizk, R., Sobh, D., Yassin, A. A. A., and Hamzeh, F. (2018) "Studying the Mindset of Corruption in the Construction Industry - A Lean Perspective." Proc., 26th Annual Conference of the International Group for Lean Construction, International Group on Lean Construction, Chennai, India, 316-325.

Samarghandi, H., Mousavi, S., Taabayan, P., Mir Hashemi, A., and Willoughby, K. (2016). "Studying the Reasons for Delay and Cost Overrun in Construction Projects: The Case of Iran." Journal of Construction in Developing Countries, 21(1), 51-84.

Sinclair, G. (2012). "Optimizing the process." Healthcare Design, 12(10), 54,56,58.

Tzortzopoulos, P., Cooper, R., Chan, P., and Kagioglou, M. (2006). "Clients' activities at the design front-end." Design Studies, 27(6), 657-683.

Wilson, V. (2014). "Research methods: sampling." Evidence Based Library and Information Practice, 9(2), 45-47.

Womack, J. P., and Jones, D. T. (1996). Lean thinking: Banish waste and create wealth in your organisation. Simon and Shuster, New York, 1-402. 